\title{
Interleukin-6 released by oral lichen planus myofibroblasts promotes angiogenesis
}

\author{
XIAO-HENG XU ${ }^{1 *}$, YANG LIU $^{1 *}$, LU FENG $^{1}$, YIN-SHEN YANG ${ }^{1}$, SHU-GUANG LIU ${ }^{2}$, \\ WEI GUO ${ }^{3}$, HUI-XI ZHOU ${ }^{2}$, ZHI-QIANG LI ${ }^{2}$, LIN ZHANG ${ }^{1}$ and WEN-XIA MENG ${ }^{1}$ \\ Departments of ${ }^{1}$ Oral Medicine, ${ }^{2}$ Oral Surgery and ${ }^{3}$ Oral Pathology, Stomatological Hospital, \\ Southern Medical University, Guangzhou, Guangdong 510280, P.R. China
}

Received February 21, 2020; Accepted August 13, 2020

DOI: $10.3892 /$ etm.2021.9722

\begin{abstract}
Oral lichen planus (OLP), defined as a potential for malignant transformation, is a chronic inflammatory disease in which abnormal angiogenesis serves a role in the malignant changes of the disease. OLP-associated fibroblasts (OLP-MFs), derived from the stroma of OLP tissues, are characterized by the presence of myofibroblasts and contribute to the secretion of pro-inflammatory cytokines, which may be involved in the molecular pathogenesis of OLP. However, the associated mechanisms of angiogenesis in OLP remain unknown. The present study aimed to verify the expression of intercellular adhesion molecular 1, vascular cell adhesion molecule 1, VEGF and CD34 in OLP, and to investigate whether IL-6 secreted by OLP-MFs promoted OLP angiogenesis and the effect of its corresponding antibody inhibition. The results of the experiments demonstrated that inflammation was present and OLP upregulated the secretion of IL-6 by OLP stromal fibroblasts, thereby enhancing OLP angiogenesis. Anti-IL-6 receptor antibody inhibited OLP-stroma IL-6 signaling and suppressed OLP angiogenesis. The antibody inhibited the inflammatory response by inhibiting the secretion of inflammatory factors, including IL-6, to suppress angiogenesis and reduce disease progression, thus indicating that this could be a potential target to develop a treatment for OLP.
\end{abstract}

\section{Introduction}

Oral lichen planus (OLP), a chronic inflammatory disease, has the potential for malignant transformation, with a high malignancy risk of erosive OLP (EOLP) (1). Previous studies demonstrated

Correspondence to: Dr Wen-Xia Meng, Department of Oral Medicine, Stomatological Hospital, Southern Medical University, 366 Jiangnan Road, Guangzhou, Guangdong 510280, P.R. China E-mail: mengwx2008@foxmail.com

${ }^{*}$ Contributed equally

Key words: oral lichen planus, oral lichen planus-associated fibroblasts, angiogenesis, IL-6, anti-IL-6 receptor antibody that angiogenesis served a major role in chronic inflammatory diseases, including Crohn's Disease, rheumatoid arthritis and atherosclerosis (1-3). Although the etiology of OLP remains unknown (4), the role of angiogenesis in the development of OLP is of considerable concern. A previous study has stated that angiogenesis is significantly increased in OLP compared with normal oral mucosa (5). To the best of our knowledge, a previous clinical study was the first to report that anti-angiogenic therapy exerted a positive effect on the management of OLP (6). Therefore, an in-depth understanding of angiogenesis is needed to provide an insight into the pathogenesis and progression of OLP, which may provide insight for clinicians for the management of OLP.

Previous studies have demonstrated that activated fibroblasts, also termed myofibroblasts (MFs), are involved in the development of neoplasms and certain inflammatory processes, such as cardiac fibrosis and cirrhosis (7-9). Portal myofibroblasts promote vascular remodeling underlying cirrhosis formation by releasing microparticles (10). A previous study suggested that OLP-associated fibroblasts acquired the characteristics of myofibroblasts (termed OLP/MFs) (11). Immunophenotypically, myofibroblasts are characterized by the expression of abundant pericellular matrix proteins, including vimentin, $\alpha$-smooth muscle actin ( $\alpha$-SMA) and fibroblast activation protein (FAP) (11). It was hypothesized that fibroblasts in OLP connective tissues affected by the inflammatory environment may be involved in the molecular pathogenesis underlying OLP.

In recent years, previous studies have reported that IL-6 produced by carcinoma-associated fibroblasts (CAFs) is critical for tumor angiogenesis $(12,13)$. However, the role of OLP/MFs in angiogenesis and whether IL- 6 promotes angiogenesis in OLP and the underlying mechanisms have not yet been reported. The present study investigated the expression of various vascular markers in OLP. Additionally, OLP/MFs were isolated and cultured in vitro and, to the best of our knowledge, the present study was the first to report the biological characteristics of OLP/MFs. This strategy aimed to elucidate whether the putative effects of IL-6 released by OLP/MFs were critical for OLP angiogenesis.

\section{Materials and methods}

Tissue collection. Human OLP specimens from patients diagnosed with OLP without epithelial dysplasia and normal 
oral squamous epithelium tissues from patients undergoing plastic surgery were collected from the Stomatological Hospital of Southern Medical University (Guangzhou, China) from January 2018 to January 2019. Patients were excluded if they had severe systemic diseases, received drug treatment in the past 4 weeks, or suffered other oral mucosal diseases. The OLP tissues were divided into EOLP and NEOLP groups. The protocol was reviewed by the Institutional Ethics Committee of this hospital [approval no. (2019)26]. Each patient signed an informed consent form. A total of 15 normal epithelium tissues and 25 OLP samples were utilized for immunohistochemistry (IHC) and the clinical features of the participants are presented in Table I. All surgically-resected tissues were collected for histopathological confirmation.

IHC analysis and microvessel density (MVD) analysis. The tissue samples were fixed in $4 \%$ formalin at room temperature for $24 \mathrm{~h}$. Sections were deparaffinized in xylene, rehydrated in an alcohol gradient and embed with epoxy resin. The $3 \mu \mathrm{m}$ thick mucosal sections were processed for histology. The antigen retrieval was performed using the wet autoclaving method in the presence of citrate buffer $\mathrm{pH}$ 6.0. The sections were blocked with $1 \% \mathrm{BSA} / \mathrm{PBS}$ at $37^{\circ} \mathrm{C}$ for $30 \mathrm{~min}$. Immunostaining for vascular cell adhesion molecule 1 (VCAM-1, also known as CD106; 1:60; cat. no. ab134047; Abcam), intercellular adhesion molecular 1 (ICAM-1, also known as CD54; 1:100; cat. no. ab222736; Abcam), VEGF (1:100; cat. no. ab46154; Abcam) and CD34 (1:500; cat. no. ab81289; Abcam) was performed using mouse monoclonal antibodies with the DakoCytomation EnVision ${ }^{\circledR}$ system (Dako; Agilent Technologies, Inc.), according to the manufacturer's protocols. The tissue was incubated with the primary antibodies overnight at $4^{\circ} \mathrm{C}$. Subsequently, the sections were incubated with anti-rabbit-HRP (1:50; cat. no. PV-9000; ZSGB-BIO.) or anti-mouse-HRP (1:50; cat. no. PV-9000; ZSGB-BIO.) at room temperature for $30 \mathrm{~min}$. The stained tissue samples were incubated with $10 \%$ normal goat serum at room temperature for $30 \mathrm{~min}$. The DAB REAL EnVision Detection System (cat. no. K5007; DAKO; Agilent Technologies, Inc.) was used for color development. Slides were counterstained with modified Harris hematoxylin (Thermo Fisher Scientific, Inc). Excess dye solution was then washed away and the slides were mounted using neutral gum mounting film. Images were captured using an inverted light microscope (magnification, x200 and x400; BX51; Olympus Corporation). Immunoreactivity was scored as: i) 0 , absent; ii) $1, \leq 25 \%$ positive cells; iii) $2,26-75 \%$ positive cells; or iv) $3,>75 \%$ positive cells. OLP were assessed from $\geq 10$ randomly selected fields using a high-power microscope (magnification, $\mathrm{x} 400$ ) and the $\%$ of positive cells was calculated. All slides were interpreted by two investigators. Immunostaining for CD34 (1:500; cat. no. ab81289; Abcam) was used to examine microvessels in normal or OLP tissue sections. Statistical analysis was performed as previously described (14).

Dual immunofluorescence staining. The tissues were fixed in $4 \%$ formalin at room temperature for $24 \mathrm{~h}$. The $3 \mu \mathrm{m}$ thick tissue sections were deparaffinized in xylene and rehydrated in an alcohol gradient. These sections were blocked with $1 \% \mathrm{BSA} / \mathrm{PBS}$ at $37^{\circ} \mathrm{C}$ for $30 \mathrm{~min}$. For dual immunofluorescence staining of tissue samples, sections were first reacted with human $\alpha$-SMA (1:500; cat. no. ab5694; Abcam) and human IL-6 antibodies (1:500; cat. no. ab6672; Abcam) overnight at $4^{\circ} \mathrm{C}$. Subsequently, the sections were treated with donkey anti-mouse-555 (1:300; cat. no. ab150110; Abcam) for $1 \mathrm{~h}$ in the dark at room temperature. DAPI (Abcam) was applied and the slides were examined with a fluorescence (DM4000; Leica Microsystems, Inc.) or confocal microscope (magnification, x200 and x400; TCS SP8; Leica Microsystems, Inc.).

Cell cultivation and associated assays. NEOLP or EOLP lesions were isolated and cultured for OLP-MFs. 8 Primary OLP-MFs and 6 normal fibroblasts (NFs) were obtained according to methods described by a previous study (12). Cultured cells at passages 3-6 were used. OLP-MFs and NFs were examined using anti-cytokeratin (1:100; cat. no. AM06387SU-N; OriGene Technologies, Inc.), anti-vimentin (1:200; cat. no. ab92547; Abcam), anti- $\alpha$-SMA (1:100; cat. no. ab5694; Abcam) and anti-FAP (1:100; cat. no. ab53066; Abcam) antibodies. Growth and viability of OLP-MFs were assessed using a Cell Counting Kit-8 (CCK-8; Dojindo Molecular Technologies, Inc.) at 24, 48 and $72 \mathrm{~h}$, according to the manufacturer's protocol. The cells were rinsed with PBS and fixed overnight in $3 \%$ glutaraldehyde at $4{ }^{\circ} \mathrm{C}$. Subsequently, the samples were dehydrated using the following ethanol gradient: 30, 50, 70, 95 and $100 \%$. The samples were then dehydrated with xylene, air-dried at room temperature and embed with epoxy resin. The specimens were coated with gold. The ultrastructure of OLP-MFs and NFs was compared using a transmission electron microscope (magnification, $\mathrm{x} 1.2 \mathrm{k}$ ) and scanning electron microscopy (magnification, $\mathrm{x} 700$ ), respectively. The images were processed using Adobe Photoshop CS6 (Version 13.0.1; Adobe Systems, Inc.).

Wound healing assays. Wound healing assays were used to detect the migration of OLP-MFs and NFs at different time points $(0,24$ and $48 \mathrm{~h})$. Cells were grown in 24 -well plates (at a seeding density of $5.0 \times 10^{6}$ cells/well) in medium (DMEM, high glucose; Gibco; Thermo Fisher Scientific, Inc.) supplemented with 10\% FBS. After the cells grow into a monolayer, the medium was discarded and a sterile pipette tip was used to scratch the center of the monolayer at the bottom of the 24-well plate, perpendicular to the marking line. The samples were rinsed with PBS solution 3 times and 1\% serum media, as aforementioned, was added. Images were captured using an inverted light microscope (TE2000; Nikon Corporation) at the aforementioned time points. The acquired images were used to calculate the migration rate of cells using the image analyzing software, Image (version 1.46r; National Institutes of Health). The $\%$ closure (\% of the surface area of the migrated cells into the defined wound area) was used to indirectly measure the cells migration rate. Closure $(\%)=($ migrated cell surface area/total surface area) $\times 100$. A total of 3 replicates of the OLP-MFs and 3 NFs cell lines were selected for reverse transcription-quantitative PCR (RT-qPCR) and western blot analysis.

$R T-q P C R$. Cells were grown in $24-w e l l$ plates (at a seeding density of $1.0 \times 10^{5}$ cells/well) were treated with $100 \mathrm{ng} / \mathrm{ml}$ Toll-like receptor ligand pg-lipopolysaccharide 
Table I. Clinical features of patients.

\begin{tabular}{lcccr}
\hline & & & \multicolumn{2}{c}{ Sex } \\
\cline { 4 - 5 } $\begin{array}{l}\text { Patient } \\
\text { group }\end{array}$ & Number & $\begin{array}{c}\text { Age, years } \\
(\text { mean } \pm \text { SD) }\end{array}$ & Female & Male \\
\hline OLP & 25 & & 16 & 9 \\
EOLP & 14 & $46.50 \pm 3.54$ & 10 & 4 \\
NEOLP & 11 & $46.82 \pm 2.71$ & 6 & 5 \\
Normal & 15 & $43.53 \pm 3.44$ & 8 & 7 \\
Total & 40 & $45.48 \pm 12.05$ & 24 & 16 \\
F-value & 0.303 & & 0.560 & \\
P-value & 0.741 & & 0.576 & \\
\hline
\end{tabular}

OLP, oral lichen planus; EOLP, erosive OLP; NEOLP, non-erosive OLP. ns, $\mathrm{P}>0.05$ Normal group vs. OLP group.

(LPS; Sigma-Aldrich; Merck KGaA) for 1-4 or 5 days and the corresponding supernatants were collected to evaluate the expression of IL-6. The subgroups were as follows: NFs, NFs-LPS stimulation, OLP/MFs and OLP/MFs-LPS. To compare the expression level of each gene, RT-qPCR was performed.Cells (seeding density, $1 \times 10^{5}$ cells/well) were seeded into 6-well plates. DNA was harvested from 3 OLP-MFs and 3 NFs primary cell lines. Total RNA from each sample was isolated using TRIzol ${ }^{\circledR}$ Universal reagent (Tiangen Biotech Co., Ltd.), according to the manufacturer's protocol. RT-qPCR was performed using the GoScript ${ }^{\mathrm{TM}}$ Reverse Transcription system (A5001; Promega Corporation) and GoTaq ${ }^{\circledR}$ qPCR Master Mix (Promega Corporation). The following thermocycling conditions were used: Initial denaturation at $95^{\circ} \mathrm{C}$ for $30 \mathrm{sec}$; followed by 40 cycles of $95^{\circ} \mathrm{C}$ for $5 \mathrm{sec}$ and $60^{\circ} \mathrm{C}$ for $30 \mathrm{sec}$. The primers used to amplify $\alpha$-SMA, IL-6, VEGF, VCAM-1 and ICAM-1 are listed in Table II. $\beta$-actin was used as the internal control. Experiments were performed in triplicate. The $2^{-\Delta \Delta \mathrm{Cq}}$ method was used for quantification (15).

Protein preparation and Simple Western analysis. A total of 3 OLP-MFs and 3 NFs were selected for Simple Western analysis. Total protein expression of $\alpha$-SMA and IL- 6 were assessed using an automated capillary electrophoresissized-based Simple Western system using a Wes machine (ProteinSimple). Simple Western is a gel-free, blot-free, capillary-based, automated protein immunodetection system that automates all the steps following sample preparation, including sample loading, size-based protein separation, immunoprobing, washing, detection and data analysis $(16,17)$. All procedures were performed using the manufacturer's reagents and according to protocol. Data were analyzed with Compass software (version 4.0; ProteinSimple). Anti- $\alpha$ smooth muscle Actin antibody (1:2,000; cat. no. ab5694; Abcam), anti-IL6 antibody (1:2,000; cat. no. ab6672; Abcam) and GAPDH (clone 6C5; 1:5,000; cat. no. MAB374-AF647; Chemicon International; Thermo Fisher Scientific, Inc.) were used, with GAPDH being used as the loading control.

ELISA. IL-6, VEGF, VCAM-1 and ICAM-1 expression levels in each cultured OLP-MFs and NFs were evaluated
Table II. Primer sequences of the investigated genes.

\begin{tabular}{ll} 
Gene & \multicolumn{1}{c}{ Primer sequences (5'-3') } \\
\hline$\alpha$-SMA & F: GTGTTGCCCCTGAAGAGCAT \\
& R: GCTGGGACATTGAAAGTCTCA \\
IL-6 & F: AATCTGGATTCAATGAGGAGACTT \\
& R: TCTGGCTTGTTCCTCACTACTCTC \\
VEGF & F: GAGGGCAGAATCATCACGAAG \\
& R: TGTACTCGATCTCATCAGGGTACTC \\
VCAM-1 & F: CATAAGAAACTGGAAAAGGGAATC \\
ICAM-1 & R: AGGGGGTACACGCTAGGAAC \\
& F: ATGCCCAGACATCTGTGTCC \\
$\beta$-actin & R: GGGGTCTCTATGCCCAACAA \\
& F: CCTGGCACCCAGCACAAT \\
& R: GCTGATCCACATCTGCTGGAA
\end{tabular}

F, forward; R, reverse; $\alpha$-SMA, $\alpha$-smooth muscle actin; IL-6, interleukin 6; VEGF, vascular endothelial growth factor; VCAM-1, vascular cell adhesion molecule 1; ICAM-1, intercellular adhesion molecular 1.

using ELISAs. NFs and OLP-MFs cell lines were seeded into 6-well plates at a density of $4 \times 10^{5}$ cells $/ \mathrm{ml}$. Following overnight incubation at $37^{\circ} \mathrm{C}$, cell lines were exposed to the conditions described in the following section and incubated with $10 \%$ FBS in DMEM. After 12, 24, 36 or $48 \mathrm{~h}$, culture supernatants were collected, centrifuged at 1,000 $\mathrm{x} \mathrm{g}$ at room temperature for $20 \mathrm{~min}$ to pellet any detached cells and measured using IL-6 ELISA Kit (cat. no. CSB-E04638h; Cusabio Technology LLC), VEGF (cat. no. DVE00; R\&D Systems, Inc.), VCAM-1 (cat. no. DVC00; R\&D Systems, Inc.) and ICAM-1 (cat. no. DCIM00; R\&D Systems, Inc.) ELISA kits, according to the manufacturer's protocols.

Effect of IL-6 on angiogenesis-associated cytokine expression. Cells were treated with $1 \mathrm{ng} / \mathrm{ml}$ IL-6 (PeproTech, Inc.), $40 \mathrm{mg} / \mathrm{ml}$ soluble Interleukin-6 receptor (sIL-6R; Prospec-Tany TechnoGene, Ltd.) and $10 \mu \mathrm{g} / \mathrm{ml}$ tocilizumab (MRA; anti-human IL-6 receptor antibody; Selleck Chemicals) for $24 \mathrm{~h}$ (RT-qPCR) or $48 \mathrm{~h}$ (ELISA) at $37^{\circ} \mathrm{C}$. VEGF, VCAM-1 and ICAM-1 mRNA expression levels were measured using RT-qPCR, as aforementioned. VEGF, VCAM-1 and ICAM-1 expression levels in cell culture supernatants were collected and measured using ELISA, as aforementioned.

Cell migration. NFs or OLP-MFs were seeded (seeding density, $1 \times 10^{6}$ cells) in serum-free medium (DMEM/F12; Gibco; Thermo Fisher Scientific, Inc.) into the upper chamber of $0.8 \mu \mathrm{m}$ Transwell inserts (Corning, Inc.). Medium (DMEM, high glucose; Gibco, Inc.) supplemented with 10\% FBS was added to the lower chamber as the chemoattractant. Following incubation for $12 \mathrm{~h}$ at $37^{\circ} \mathrm{C}$, non-migrated-cells were carefully removed from the upper membrane surface using a cotton tip and cells that passed through the filter were fixed with $4 \%$ paraformaldehyde for $20 \mathrm{~min}$ and stained with hematoxylin for $30 \mathrm{~min}$ at room temperature. Cells were observed 


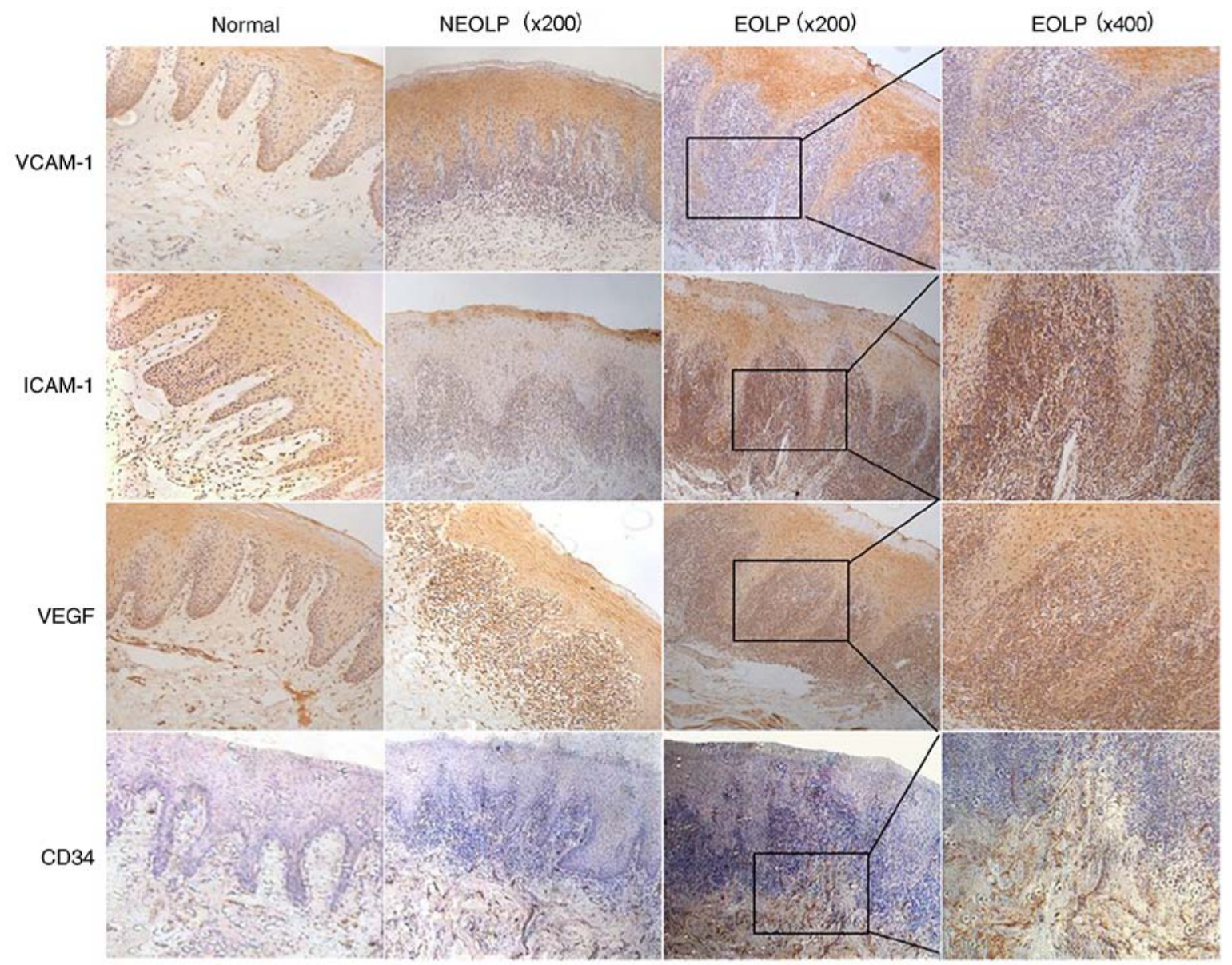

Figure 1. ICAM-1, VCAM-1, VEGF and CD34 expression in OLP. In normal tissues, the levels of VCAM-1, ICAM-1 and VEGF were nearly undetectable. In normal oral squamous epithelium, low cytoplasmic expression of ICAM-1 and moderate expression of VCAM-1, VEGF and CD34 was detected. In OLP tissues, there was a moderate-to-intense homogeneous cytoplasmic expression of ICAM-1, VCAM-1, VEGF and CD34. Microvessel density analysis demonstrated that the numbers of CD34-stained brown-colored blood vessels increased gradually from normal tissues to NEOLP and EOLP tissues. ICAM-1, intercellular adhesion molecular 1; VCAM-1, vascular cell adhesion molecule 1; VEGF, vascular endothelial growth factor; CD, cluster of differentiation; OLP, oral lichen planus; NEOLP, non-erosive OLP; EOLP, erosive OLP.

under a light microscope (x100) and images were captured using a digital camera.

Tube formation assay. Human umbilical vein endothelial cells (HUVECs) were purchased from Procell Life Science \& Technology Co., Ltd.. A 96-well plate pre-coated with Matrigel was incubated at $37^{\circ} \mathrm{C}$ for $2 \mathrm{~h}$. Following this, $2 \times 10^{4}$ HUVECs/well suspended in $100 \mu \mathrm{l}$ conditioned medium were added with IL-6/sIL-6R and MRA by groups, and the groups were as follow: NFs/OLP-MFs + HUVECs, NFs/OLP-MFs + HUVECs + IL-6/sIl-6R, NFs/OLP-MFs + HUVECs + IL-6/sIl-6R + MRA. Following incubation at $37^{\circ} \mathrm{C}$ for $24 \mathrm{~h}$, three fields were chosen at random, the number of capillary-like tubes were counted, and the number of branch points, number of branches and tube length were measured. Images were captured using an inverted microscope (x100) (TE2000; Nikon Corporation).

Statistical analysis. Data were analyzed using SPSS software (version 22.0; IBM Corp.). Student's t-test and one-way ANOVAs were used to evaluate differences between sample groups when appropriate and Fisher's least significant difference (LSD) test was used as the post hoc test. Data are presented as the mean \pm SEM. $\mathrm{P}<0.05$ was considered to indicate a statistically significant difference.

\section{Results}

VCAM-1, ICAM-1, VEGF and CD34 expression in OLP. To verify the expression of VCAM-1, ICAM-1, VEGF and CD34 in clinical samples and fully assess their association with the severity of OLP, 15 oral normal squamous epithelium tissues and 25 OLP tissues were examined. The results of IHC demonstrated that the expression levels of VCAM-1, ICAM-1, VEGF and CD34 were nearly undetectable in normal stromal cells (Fig. 1). Notably, low cytoplasmic expression of ICAM-1 and moderate expression of VCAM-1, VEGF and CD34 was detected in the normal tissues. Conversely, moderate-to-intense homogeneous cytoplasmic expression was observed in the OLP tissues and the positive staining in EOLP was significantly higher compared with non-erosive OLP (NEOLP), as shown in Fig. 1. Based on the number of positive cells, the expression of angiogenesis factors in OLP tissues was significantly higher compared with normal tissues. The results of the immunoreactivity assay of ICAM-1, VCAM-1 and VEGF in normal and OLP tissues is presented in Table III. MVD were observed 

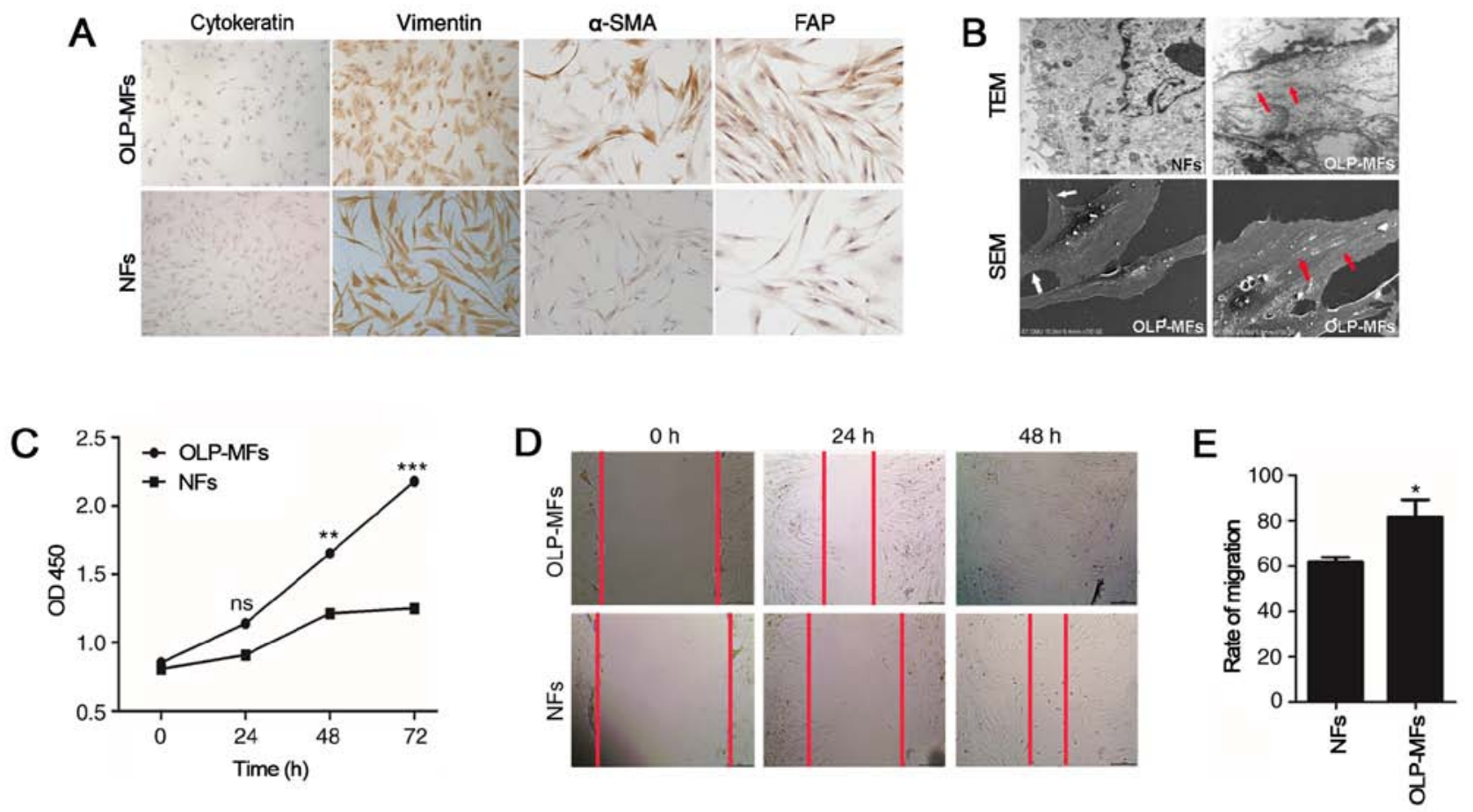

Figure 2. Fibroblasts isolated from specimens. (A) All cultured cells were positive for vimentin and negative for cytokeratin. OLP-MFs exhibited an elevated level of $\alpha$-SMA and FAP. NFs did not express $\alpha$-SMA or FAP. Magnification, x200. (B) Transmission electron microscopy (x1.2k) demonstrated typical morphological structures, including large spindle shapes, peripheral filaments and focal density in OLP-MFs (red arrow). These were absent in the NFs. Scanning electron microscopy (x700) revealed that OLP-MFs exhibited fusiform or polygonal shapes with slab-shaped pseudopods (white arrow) and a pile of elastic fibers (red arrow) resembling smooth muscles that are formed in the cytoplasm and usually arranged parallel to the cell axis, while NFs present long and thin spindle shape. (C) Cell Counting Kit-8 assays demonstrated that OLP-MFs had a significantly higher hyperplasia ability compared with NFs. (D) Wound healing assays revealed that increased numbers of OLP-MFs migrated compared with NFs. Magnification, $x 40$. (E) The migration rate of OLP-MFs was higher compared with NFs. ${ }^{*} \mathrm{P}<0.05,{ }^{* *} \mathrm{P}<0.01,{ }^{* * *} \mathrm{P}<0.001$ vs. NFs. OLP, oral lichen planus; MFs, myofibroblasts; $\alpha$-SMA, $\alpha$-smooth muscle actin; FAP, fibroblast activation protein; NFs, normal fibroblasts; OD, optical density; ns, not significant; TEM, transmission electron microscopy; SEM, scanning electron microscopy.

Table III. Comparison of ICAM-1, VCAM-1 and VEGF positive cells between groups.

\begin{tabular}{lccc}
\hline Group & ICAM-1 & VCAM-1 & VEGF \\
\hline Normal & $1.99 \pm 3.67 \%$ & $2.33 \pm 4.28 \%$ & $3.20 \pm 5.40 \%$ \\
OLP & $36.96 \pm 15.59 \%$ & $29.32 \pm 6.06 \%$ & $41.56 \pm 15.99 \%$ \\
t-value & -10.74 & -15.09 & -10.99 \\
P-value & $\mathrm{P}<0.001$ & $\mathrm{P}<0.001$ & $\mathrm{P}<0.001$ \\
\hline
\end{tabular}

$\mathrm{P}<0.001$ normal group vs. OLP group. ICAM-1, intercellular adhesion molecular 1; VCAM-1, vascular cell adhesion molecule 1; VEGF, vascular endothelial growth factor; OLP, oral lichen planus.

in the inflammatory infiltrating area and surrounding areas (Fig. 1). The statistical results are presented in Table IV. In the present study, the mean MVD in OLP tissues (NEOLP and EOLP) was significantly higher compared with normal tissues $(\mathrm{P}<0.001)$. Additionally, the mean MVD of the EOLP group was obviously higher than that in the NEOLP group $(\mathrm{P}<0.001)$.

Characteristics of fibroblasts isolated from normal and OLP specimens. A total of 8 primary human OLP/MFs lines and 6 primary oral NFs lines were derived from oral mucosa and cultured successfully. All cultured cells were positive for vimentin; however, all cells were negative for cytokeratin
Table IV. Comparison of MVD between groups.

\begin{tabular}{llll}
\hline & $\begin{array}{c}\text { MVD } \\
\text { Group }\end{array}$ & & \\
\hline Normal tissues group \pm SD) & $23.05 \pm 6.58$ & $-7.171^{\mathrm{a}}$ & $\mathrm{P}<0.001^{\mathrm{a}}$ \\
OLP tissues group & $58.82 \pm 11.44$ & $-4.982^{\mathrm{b}}$ & $\mathrm{P}<0.001^{\mathrm{b}}$ \\
$\quad$ NEOLP group & $87.89 \pm 15.45$ & & \\
EOLP group & & & \\
\hline
\end{tabular}

${ }^{\mathrm{a}} \mathrm{P}<0.05$ vs. OLP tissues group; ${ }^{\mathrm{b}} \mathrm{P}<0.001$ vs. EOLP group. MVD, microvessel density; OLP, oral lichen planus; EOLP, erosive OLP; NEOLP, non-erosive OLP.

(Fig. 2A). The expression of $\alpha$-SMA is a defining feature of MFs and CAFs (18). Immunostaining for intracellular cytoskeletal proteins demonstrated an increased proportion of $\alpha$-SMA and FAP antibody expression in OLP-MFs. However, neither were expressed by NFs. Transmission electron microscopy demonstrated typical morphological structures in OLP-MFs cells, including large spindle shapes, peripheral filaments and focal density (red arrow), which were absent in NFs (Fig. 2B). Moreover, scanning electron microscopy demonstrated that OLP-MFs exhibited fusiform or polygonal shapes with slab-shaped pseudopods (white arrow) and a pile of elastic fibers (white arrow) resembling smooth muscles that 

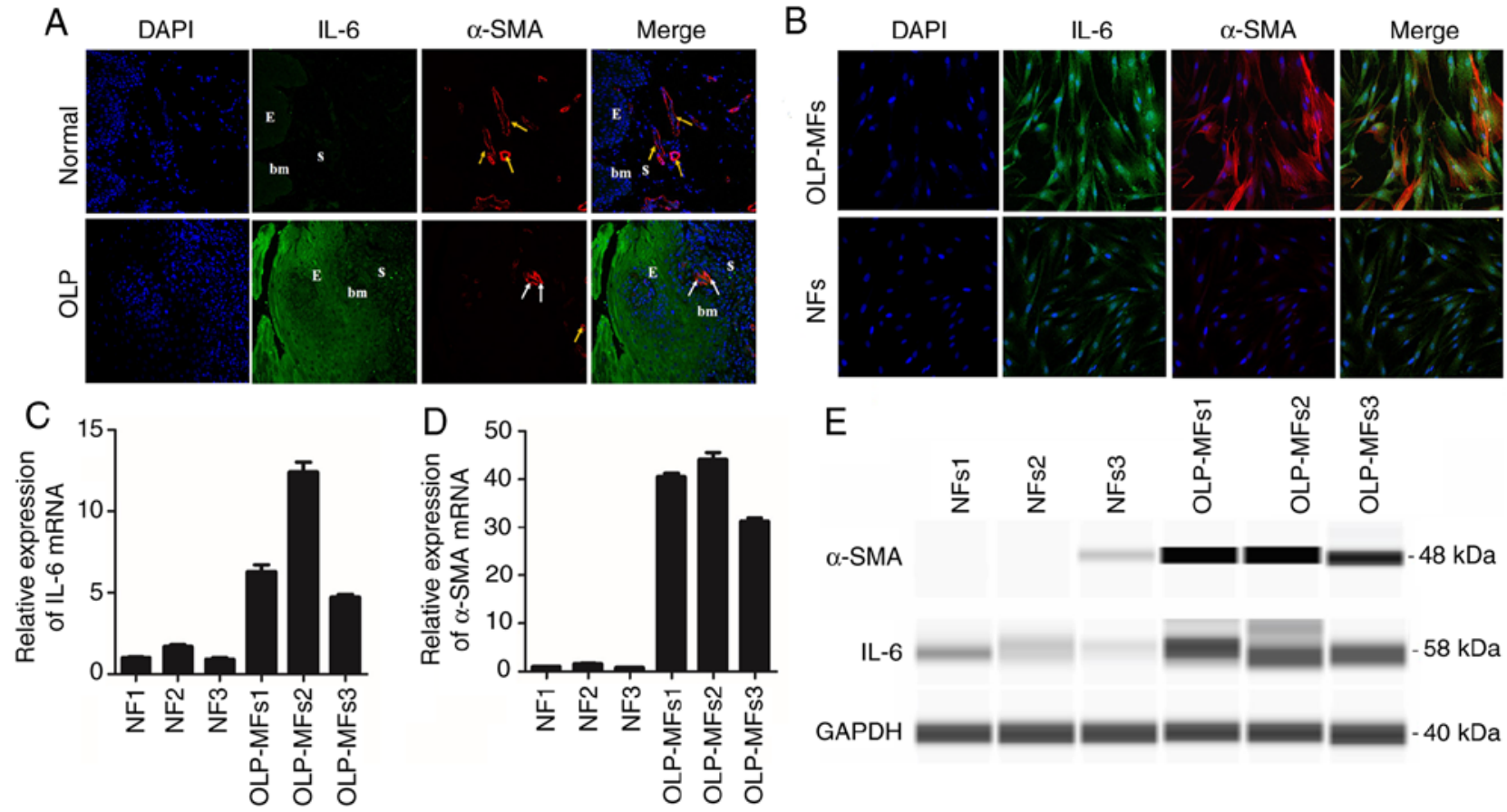

Figure 3. IL-6 is primarily released from fibroblasts in vitro. (A) In OLP tissues, IL- 6 was intensely detected in the epithelium and stroma, and certain $\alpha$-SMA positive, non-blood vessel, spindle-shaped cells (white arrows) were positioned beneath the squamous. In normal tissues, IL-6 was mainly negative in the epithelium and stroma, and $\alpha$-SMA-positive vascular endothelial cells (yellow arrows) formed as vessels. Magnification, x200. (B) The same field of view revealed that all OLP-MFs were positive for IL-6 and $\alpha$-SMA, whereas NFs were weakly stained for IL-6 and slightly positive for $\alpha$-SMA. Magnification, $x 400$. In OLP-MFs, the relative mRNA expression of (C) IL- 6 and (D) $\alpha$-SMA was higher compared with NFs. (E) The results of Simple Western analysis demonstrated that the expression of $\alpha$-SMA (48 kDa) and IL-6 (58 kDa) in OLP-MFs was detected. NFs exhibited weak IL-6 expression and rare expression of $\alpha$-SMA protein. IL-6, interleukin 6; OLP, oral lichen planus; $\alpha$-SMA, $\alpha$-smooth muscle actin; MFs, myofibroblasts; NFs, normal fibroblasts; E, epithelium; S, stroma; bm, basement membrane.

are formed in the cytoplasm and usually arranged in parallel to the cell axis. The biological characteristics of OLP-MFs were evaluated by CCK- 8 assays, which revealed that the OLP-MFs exhibited a significantly higher hyperplasia ability compared with NFs at 48 and 72 h post-culture (Fig. 2C). Furthermore, wound healing assays were conducted to investigate the migratory ability of OLP-MFs. The scratch width of OLP-MFs and NFs at 24 and $48 \mathrm{~h}$ was markedly narrower compared with $0 \mathrm{~h}$ (Fig. 2D). Additionally, at both time points, increased numbers of OLP-MFs migrated compared with NFs. Statistically, the rate of migration of OLP-MFs was $80 \%$, whereas that of NFs was $60 \%$ (Fig. 2E). These results indicated that certain specific ultrastructures in OLP-MFs changed and that OLP-MFs exhibited higher proliferative and migratory abilities compared with NFs.

Increased IL-6 is released from MFs compared with NFs in vitro. Dual immunofluorescence staining of normal tissues demonstrated that IL- 6 was not expressed in the epithelium or stroma, whereas IL-6 was notably detected in the epithelium and stroma in OLP tissues (Fig. 3A). Certain $\alpha$-SMA-positive, non-blood vessel and spindle-shaped cells (white arrows) were positioned beneath the squamous epithelium in OLP tissues. Moreover, $\alpha$-SMA-positive vascular endothelial cells (yellow arrows) formed as vessels. The combined images confirmed this result. Furthermore, regions of normal specimens were scarcely stained for IL- 6 and $\alpha$-SMA was rarely expressed in the lamina propria. Immunofluorescence staining demonstrated that most OLP-MFs were positive for IL- 6 and $\alpha$-SMA, whereas NFs were weakly stained for IL-6 and $\alpha$-SMA (Fig. 3B).
Moreover, gene expression and secretion of IL-6 in NFs and OLP-MFs were evaluated $(n=3)$. RT-qPCR reported that the relative mRNA expression of IL- 6 in OLP-MFs was 5-6 times higher compared with NFs (Fig. 3C), whereas that of $\alpha$-SMA in OLP-MFs was 30-40-fold higher as compared with NFs (Fig. 3D). Simple Western analysis demonstrated 48-kDa and 58-kDa bands in OLP-MFs, which were consistent with the size of $\alpha$-SMA and IL-6, respectively (Fig. 3E). In NFs, weak IL- 6 bands were expressed, whereas $\alpha$-SMA bands were barely detected. As $\alpha$-SMA is an indicator of MFs, these results revealed that OLP-MFs were a crucial source of IL-6.

Inflammation promotes IL-6 expression by stromal fibroblasts. ELISA results revealed that the expression of IL- 6 peaked on day 3 or 4 in the four subgroups, NFs, NFs-LPS stimulation, OLP/MFs and OLP/MFs-LPS, and then declined (Fig. 4A). LPS is known to promote the inflammation and secretion of inflammatory factors (5). The secretion of IL-6 by NFs was increased following LPS stimulation, which was similar to the expression level of OLP-MFs (Fig. 4A). These data indicated that inflammation increased the secretion of IL-6 in fibroblasts. Irrespective of the stimulation of OLP-MFs by LPS, the overall expression level of IL- 6 was higher compared with the NFs groups. RT-qPCR results demonstrated that the expression of IL- 6 mRNA in OLP-MFs was significantly higher compared with NFs at the four time points $(0,12,24$ and $48 \mathrm{~h}$; Fig. 4B) and protein expression levels revealed similar results (Fig. 4C). Therefore, RT-qPCR and Simple Western analysis results reported that the expression of IL-6 in OLP-MFs decreased with time and that NFs exhibited non-significant, 
A

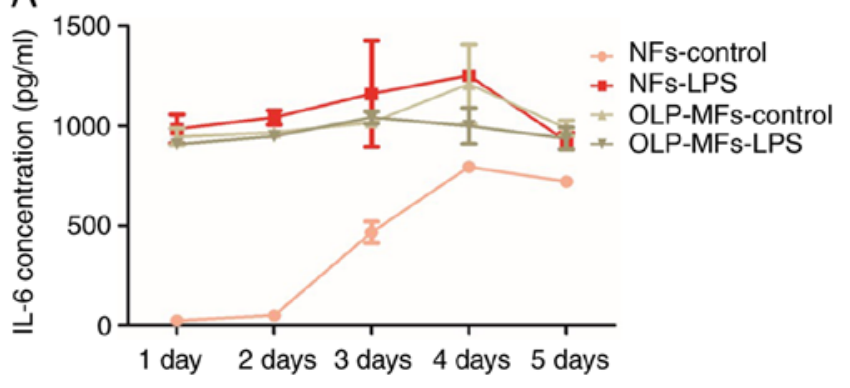

B

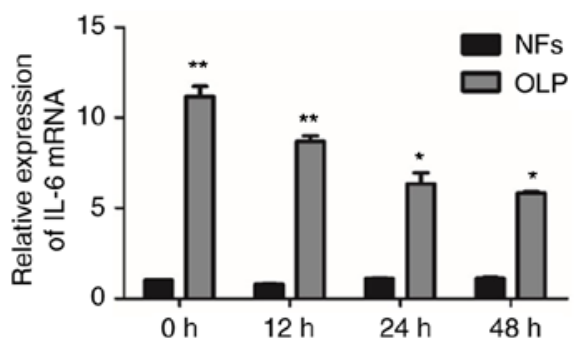

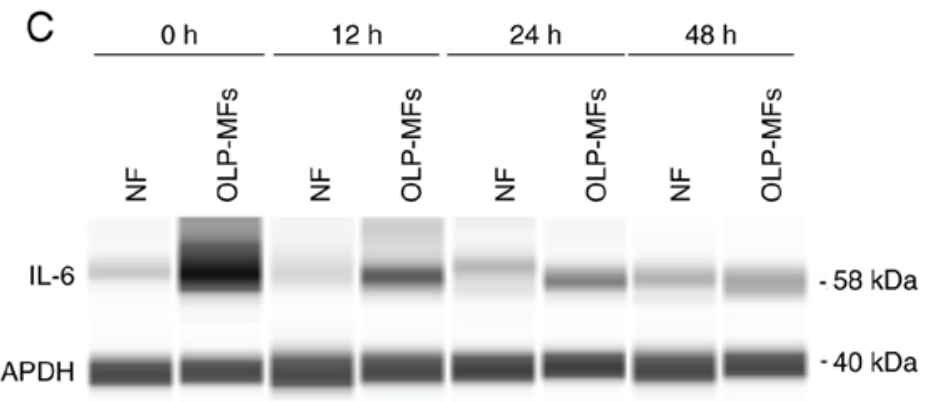

Figure 4. Inflammation promotes IL-6 expression. (A) ELISA demonstrated that the overall expression levels of IL-6 the OLP-MF groups were similar and significantly higher compared with the NF groups, and the secretion of IL-6 by NFs was significantly increased following LPS stimulation. (B) Reverse transcription-quantitative PCR and (C) Simple Western analysis demonstrated that the expression of IL-6 mRNA and protein in OLP-MFs was significantly higher compared with NFs at the four time points. Furthermore, the expression of IL-6 in OLP-MFs decreased with time. ${ }^{*} \mathrm{P}<0.05,{ }^{* * *} \mathrm{P}<0.01$ vs. NFs. IL-6, interleukin 6; OLP, oral lichen planus; MFs, myofibroblasts; NFs, normal fibroblasts; LPS, lipopolysaccharide.
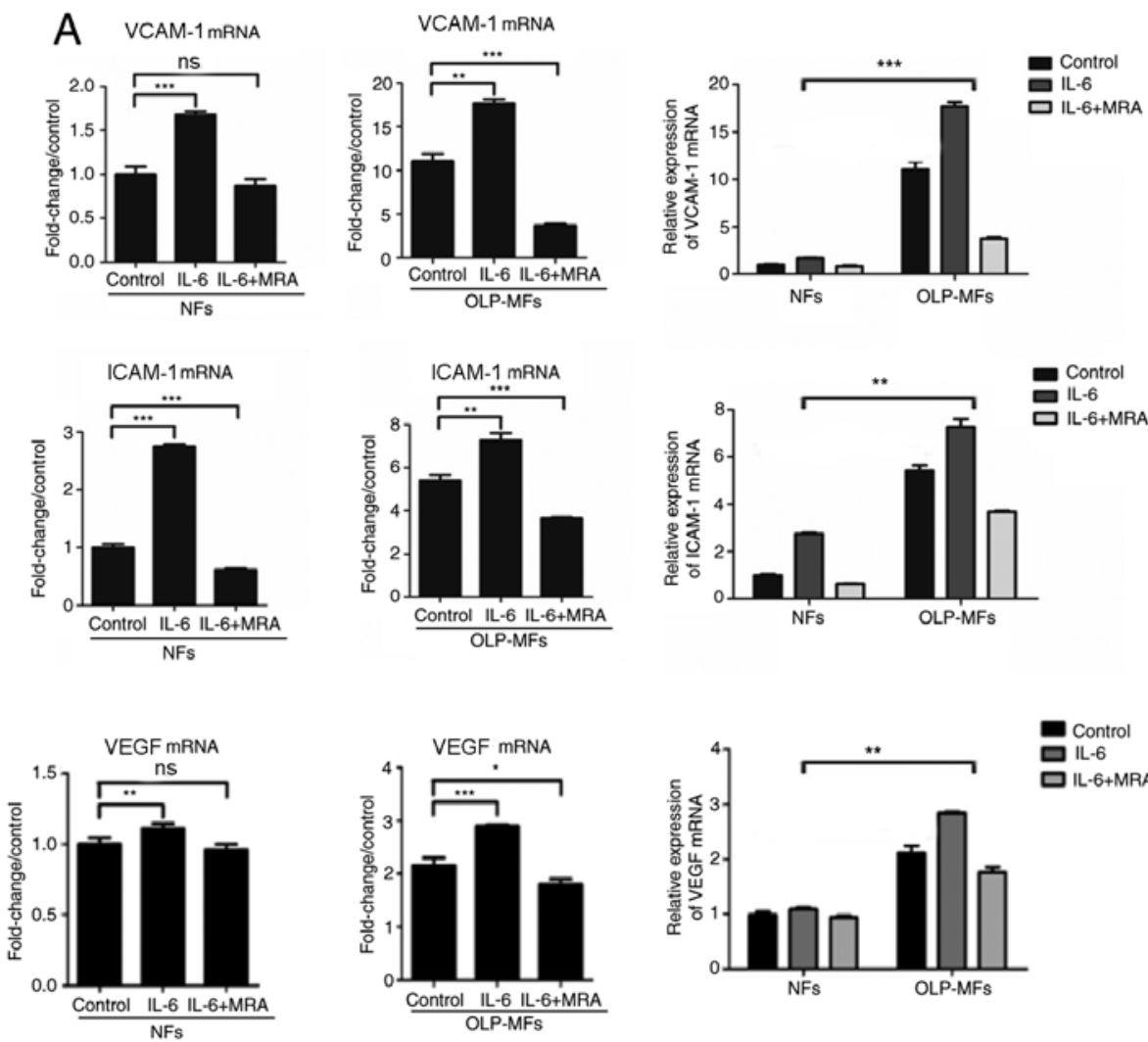

B
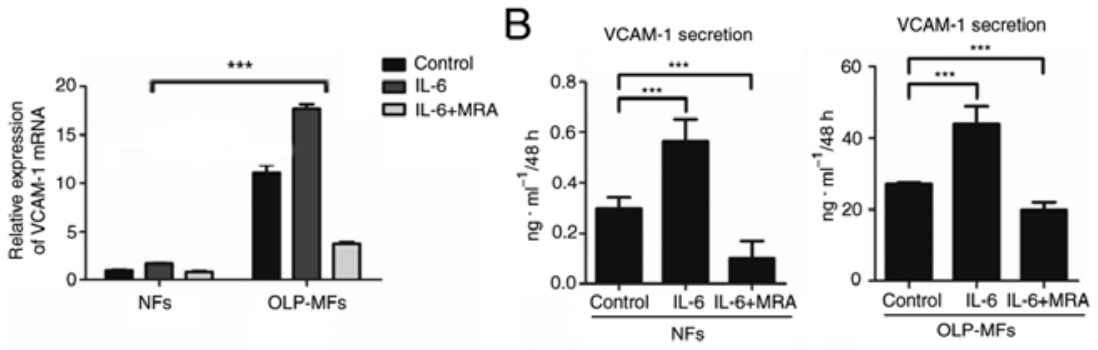

ICAM-1 secretion

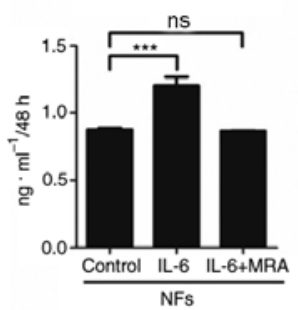

ICAM-1 secretion
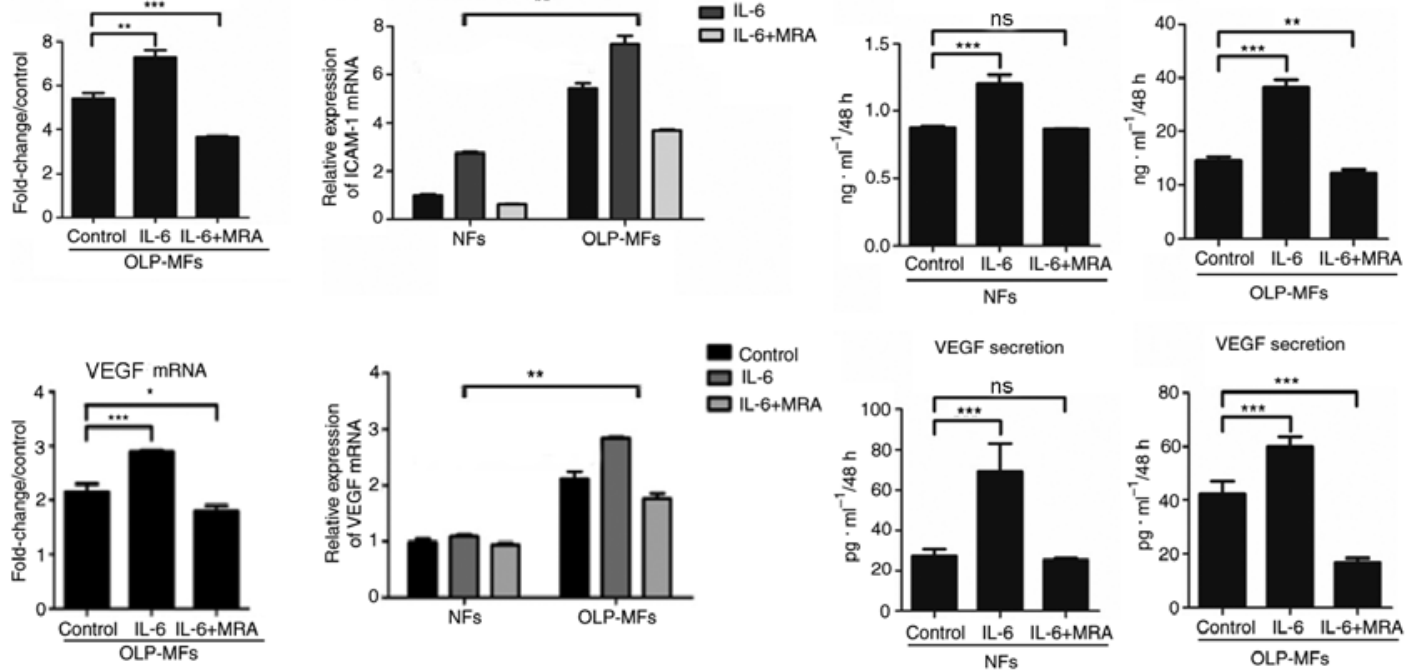

Figure 5. IL-6 promotes VCAM-1, ICAM-1 and VEGF expression. (A) Reverse transcription-quantitative PCR and (B) ELISA demonstrated that IL-6 significantly promoted the expression of VCAM-1, ICAM-1, and VEGF in OLP-MFs and NFs. MRA significantly decreased the secretion of vascular-related growth factors in the OLP-MFs group compared with the control group. The expression of angiogenesis-associated cytokines in the OLP-MFs group were significantly higher compared with the NFs group. Control group, cells without treatment; IL-6 group, cells were treated with IL-6/sIL-6R; IL-6+MRA group, cells were treated with IL-6/sIL-6R and MRA. ${ }^{*} \mathrm{P}<0.05,{ }^{* *} \mathrm{P}<0.01$ and ${ }^{* * *} \mathrm{P}<0.001$. IL-6, interleukin 6; VCAM-1, vascular cell adhesion molecule 1; ICAM-1, intercellular adhesion molecular 1; VEGF, vascular endothelial growth factor; OLP, oral lichen planus; MFs, myofibroblasts; NFs, normal fibroblasts; MRA, tocilizumab; ns, not significant. 


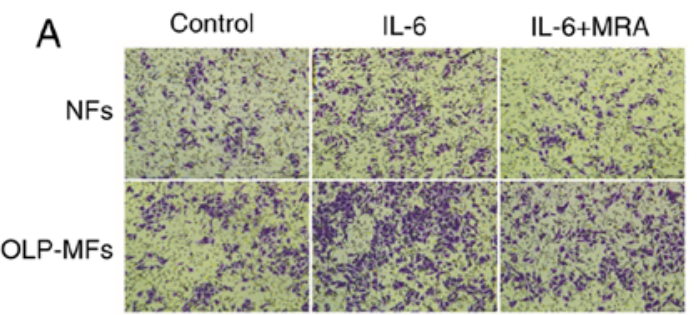

B

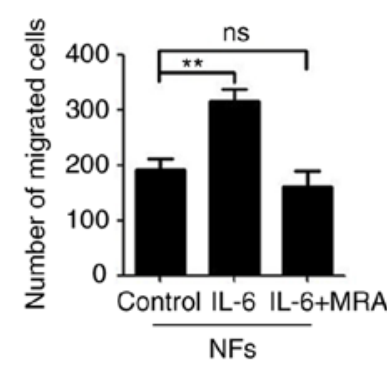

E

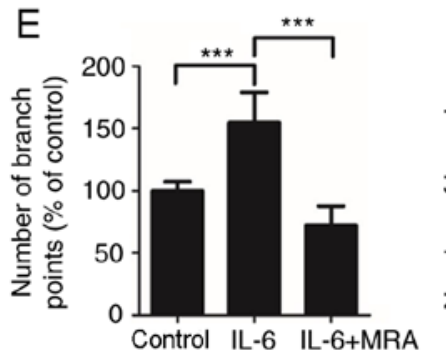

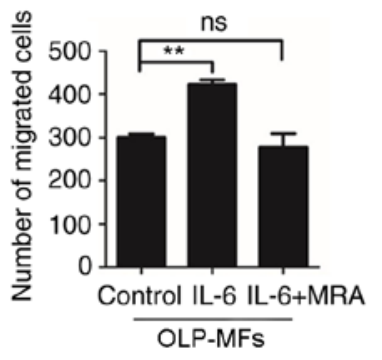

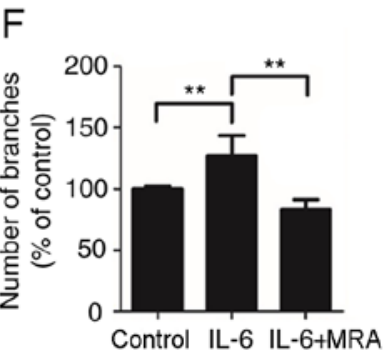

D

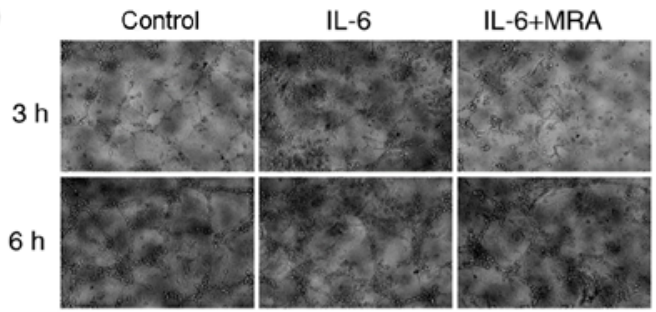

C

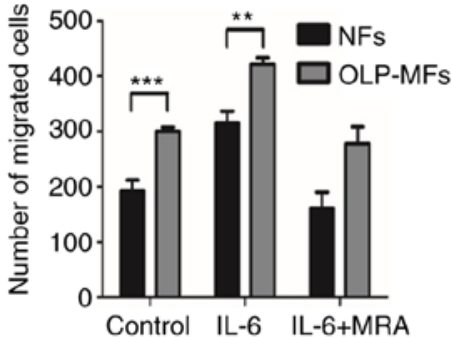

G

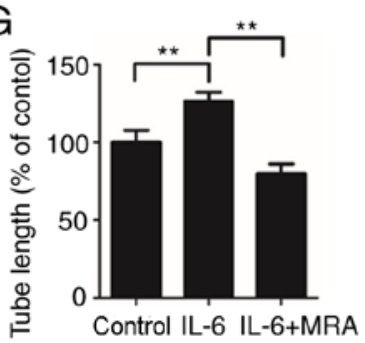

Figure 6. IL-6 promotes the angiogenic potential of HUVECs. (A) Cell migration assays demonstrated that OLP-MFs exhibited a stronger migratory ability compared with NFs. Magnification, x 100. (B) Numbers of migrated NF and OLP-MF cells in the IL-6/sIL-6R treated group were significantly higher compared with the control group. (C) MRA inhibited the migratory ability of NFs and OLP-NFs. The results of the Matrigel capillary germination assays demonstrated that following treatment with IL-6/sIL-6R, (D) abundant HUVECs had formed into blood vessels and the (E) numbers of capillary branch points, (F) numbers of blood vessel branches and (G) tube lengths formed by HUVECs were significantly higher compared with the blank group. Magnification, x100. The number and density of blood vessels formed by HUVECs were significantly reduced following MRA treatment compared with the IL-6/sIL-6R treatment group. ${ }^{* *} \mathrm{P}<0.01$ and ${ }^{* * *} \mathrm{P}<0.001$. IL-6, interleukin 6; HUVECs, human umbilical vein endothelial cells; OLP, oral lichen planus; MFs, myofibroblasts; NFs, normal fibroblasts; ns, not significant; MRA, tocilizumab; sIL-6R, soluble interleukin-6 receptor.

weak IL-6 expression. Thus, IL-6 was primarily derived from OLP-MFs and inflammatory reactions, and was gradually secreted into the culture supernatants.

IL-6 promotes VCAM-1, ICAM-1 and VEGF expression by fibroblasts, particularly by OLP-MFs. To further clarify whether IL-6 promoted angiogenesis, NFs and OLP-MFs were grouped for the treatment with IL-6/sIL-6R and MRA. The relative mRNA expression of VCAM-1, ICAM-1 and VEGF was significantly increased in OLP-MFs and NFs stimulated by IL-6/sIL-6R, compared with the control group. However, the expression of VCAM-1, ICAM-1 and VEGF was decreased in OLP-MFs and NFs following treatment with $10 \mu \mathrm{g} / \mathrm{ml}$ MRA, compared with the IL-6/sIL-6R treatment (Fig. 5A). In terms of changes in overall expression levels, the relative mRNA expression of angiogenesis-associated cytokines in the NFs group treated with IL-6/sIL-6R and MRA was similar to the OLP/MFs group; however, the expression of VCAM-1, ICAM-1 and VEGF in the OLP-MFs group was still significantly higher than the NFs group, when cells were treated with IL-6/sIL-6R (Fig. 5A). ELISA results revealed that IL-6 significantly promoted the secretion of VCAM-1, ICAM-1 and VEGF in OLP-MFs and NFs compared with the control group (Fig. 5B). MRA significantly decreased the secretion of vascular-related growth factors by OLP-MFs compared with the control group (Fig. 5B).

IL-6 signaling by OLP-MFs promotes the angiogenic potential of HUVECs. Cell migration assays demonstrated that IL-6 promoted the migratory ability of OLP-MFs and NFs (Fig. 6A). Notably, OLP-MFs exhibited stronger migratory ability compared with NFs. Moreover, MRA weakly suppressed the migratory ability of OLP-MFs and NFs compared with the control group. Statistically, the numbers of migrated OLP-MF and NF cells were significantly increased in the IL-6/sIL-6R-treated group compared with the control group $(\mathrm{P}<0.01)$ (Fig. 6B). However, there was no significant difference in numbers of migrated cells following MRA treatment compared with the IL-6/siL-R-treated group in both cell groups. Numbers of migrated OLP-MFs and NFs in the MRA-treated group did not differ significantly with the control group (Fig. 6C).

Matrigel capillary germination assays were used to analyze the effects of IL-6/sIL-6 and MRA on the angiogenic potential of HUVECs in vitro. The results demonstrated that HUVECs formed capillary buds at $3 \mathrm{~h}$ (Fig. 6D). Furthermore, numerous HUVECs formed into blood vessels post-IL-6/sIL-6R treatment and markedly blood vessel density was measured. The 
formation of blood vessels was highest at $6 \mathrm{~h}$. Moreover, the number and density of blood vessels formed by HUVECs were markedly reduced following treatment with MRA. Numbers of capillary branch points (Fig. 6E) and blood vessel branches (Fig. 6F), and tube lengths (Fig. 6G) formed by IL-6/sIL-6R-treated HUVECs were significantly higher compared with the control group. Following the addition of MRA, the three indexes were significantly lower compared with the IL-6/sIL-6R treatment group.

\section{Discussion}

OLP has been regarded as a non-specific inflammatory condition due to its pathological and micrographic features, including band-like infiltration of superficial lymphocytes in the lamina propria and infiltration of inflammatory cytokines (19). Angiogenesis is of considerable concern during the development of chronic inflammatory disorders (20-23). Previous IHC-based studies reported a strong involvement of the angiogenic phenomenon in the malignant transformation of precancerous lesions, including OLP (24-26). VEGF, ICAM-1 and VCAM-1 have been regarded as critical angiogenic factors that directly mediate OLP angiogenesis $(27,28)$. Additionally, the current IHC data demonstrated the high expression of angiogenic factors in OLP tissues according to the percentage of stained cells. Additionally, MVD in OLP tissue increased with the deterioration of the lesion. Previous results, together with those from the present study, indicated that increased angiogenesis may serve a vital role in the malignant transformation of OLP $(29,30)$. However, the mechanism underlying this phenomenon remains unclear. The dynamic interplay between multiple cell types, including MFs, immune cells, endothelial cells and adipocytes, in the microenvironment of the lesion has gained interest as a promising target for the treatment of inflammatory diseases (31). Previous studies have demonstrated that MFs and NFs produce significant amounts of IL- 6 in the presence of cancer cells $(32,33)$. Furthermore, IL-6 stimulation significantly increased the expression of VEGF in stroma fibroblasts. Therefore, it was hypothesized that IL-6 released by MFs is critical for OLP angiogenesis.

In order to verify this hypothesis, eight primary OLP-MF lines were isolated and cultured. OLP-MFs acquired characteristics and biological behavior of MFs, including the expression of $\alpha$-SMA and FAP markers (34). To identify these stromal cells dual immunofluorescence staining was used and combined with observation of the morphology of the isolated cells. Notably, OLP-MFs exhibited a significantly high expression of IL-6 at the mRNA and protein levels as compared with NFs. Additionally, fibroblasts produced IL-6 under inflammatory conditions and markedly upregulated the level of IL- 6 following treatment with LPS. To the best of our knowledge, this is the first report of the expression of IL-6 in OLP stroma fibroblasts. Furthermore, the present study demonstrated that IL- 6 facilitated OLP angiogenesis via the induction of angiogenesis-related proteins in OLP-MFs. The secreted angiogenic factors from OLP-MFs subsequently induced angiogenesis. The current results indicated that IL-6-stimulated OLP-MFs significantly facilitated the migration of HUVECs and tube length formation. Based on this model, it was concluded that IL-6-induced inflammation in OLP-MFs induced the surrounding activated fibroblasts to express VEGF, ICAM-1 and VCAM-1. Consequently, angiogenesis was induced. In a previous study, anti-human IL-6 receptor antibodies were used to remove the blockade of the IL-6 receptor (35). MRA successfully inhibited cell migration and tube formation. IL- 6 was observed to be one of the primary inductors of OLP angiogenesis; however, there are still other associated mechanisms that require further research. Therefore, OLP-MFs serve a major role in mediating IL-6-induced OLP angiogenesis. Thus, we hypothesized that the modulation between OLP-MFs and angiogenesis may have a primary role in the pathological process underlying OLP.

Taken together, these data indicated that increased angiogenesis was a common event and served a critical role in OLP pathogenesis. OLP-MFs and NFs produced significant amounts of IL-6 in the presence of inflammatory factors. Therefore, the anti-IL- 6 receptor antibodies and the target OLP-MFs may serve as novel therapeutic agents capable of inhibiting the malignant transformation of OLP.

\section{Acknowledgements}

Not applicable.

\section{Funding}

The present study was funded by the National Natural Science Foundation of China (grant no. 81500850) and the Nonprofit Industry Research Specific Fund of National Health and Family Planning Commission of China (grant no. 201502018).

\section{Availability of data and materials}

The datasets used and/or analyzed during the present study are available from the corresponding author on reasonable request.

\section{Authors' contributions}

XHX and YL contributed to the conception and design of the present study, performed the data acquisition and interpretation, and drafted and critically revised the manuscript. LF contributed to the conception, data acquisition and analysis, and drafted and critically revised the manuscript. YSY contributed to the data acquisition and interpretation, and drafted and critically revised the manuscript. SGL, WG and HXZ contributed to the data acquisition and analysis, and critically revised the manuscript. ZQL and LZ ccontributed to the data acquisition and critically revised the manuscript. WXM contributed to the conception, design, data analysis and interpretation, and drafted and critically revised the manuscript. All authors read and approved the final manuscript.

\section{Ethics approval and consent to participate}

The present study was reviewed by the Institutional Ethics Committee of the Stomatological Hospital, Southern Medical University, Guangzhou, China [approval no. (2019)26]. Each patient signed the informed consent form. 


\section{Patient consent for publication}

Not applicable.

\section{Competing interests}

The authors declare that they have no competing interests.

\section{References}

1. Rode M and Kogoi-Rode M: Malignant potential of the reticular form of oral lichen planus over a 25 -year observation period in 55 patients from Slovenia. J Oral Sci 44: 109-111, 2002.

2. Brown RS, Bottomley WK, Puente E and Lavigne GJ: A retrospective evaluation of 193 patients with oral lichen planus. J Oral Pathol Med 22: 69-72, 1993.

3. Lanfranchi-Tizeira HE, Aguas SC and Sano SM: Malignant transformation of atypical oral lichen planus: A review of 32 cases. Med Oral 8: 2-9, 2003 (In English, Spanish).

4. Malekzadeh H, Robati M, Yousefimanesh H, Ghafourian Boroujerdnia M and Nadripour R: Salivary interferon gamma and interleukin-4 levels in patients suffering from oral lichen planus. Cell J 17: 554-558, 2015.

5. Al-Hassiny A, Friedlander LT, Parachuru VPB, Seo B, Hussaini HM and Rich AM: Upregulation of angiogenesis in oral lichen planus. J Oral Pathol Med 47: 173-178, 2018.

6. Mahmoud MM and Afifi MM: Anti-angiogenic therapy (bevacizumab) in the management of oral lichen planus. Eur J Oral Sci 124: 119-126, 2016.

7. Meng W, Wu Y, He X, Liu C, Gao Q, Ge L, Wu L, Liu Y, Guo Y, Li X, et al: A systems biology approach identifies effective tumor-stroma common targets for oral squamous cell carcinoma. Cancer Res 74: 2306-2315, 2014

8. She G, Ren YJ, Wang Y, Hou MC, Wang HF, Gou W, Lai BC, Lei T, Du XJ and Deng XL: $\mathrm{K}_{\mathrm{Ca}} 3.1$ channels promote cardiac fibrosis through mediating inflammation and differentiation of monocytes into myofibroblasts in angiotensin II-treated rats. J Am Heart Assoc 8: e010418, 2019.

9. Cadamuro M, Brivio S, Mertens J, Vismara M, Moncsek A, Milani C, Fingas C, Cristina Malerba M, Nardo G Dall'Olmo L, et al: Platelet-derived growth factor-D enables liver myofibroblasts to promote tumor lymphangiogenesis in cholangiocarcinoma. J Hepatol 70: 700-709, 2019

10. Lemoinne S, Cadoret A, Rautou PE, El Mourabit H, Ratziu V, Corpechot C, Rey C, Bosselut N, Barbu V, Wendum D, et al: Portal myofibroblasts promote vascular remodeling underlying cirrhosis formation through the release of microparticles. Hepatology 61: 1041-1055, 2015.

11. Wang L, Yang Y, Xiong X, Yu T, Wang X, Meng W, Wang H, Luo G and Ge L: Oral lichen-planus-associated fibroblasts acquire myofibroblast characteristics and secrete pro-inflammatory cytokines in response to Porphyromonas gingivalis lipopolysaccharide stimulation. BMC Oral Health 18 : $197,2019$.

12. Karakasheva TA, Lin EW, Tang Q, Qiao E, Waldron TJ, Soni M, Klein-Szanto AJ, Sahu V, Basu D, Ohashi S, et al: IL-6 mediates cross-talk between tumor cells and activated fibroblasts in the tumor microenvironment. Cancer Res 78: 4957-4970, 2018.

13. Mirkeshavarz M, Ganjibakhsh M, Aminishakib P, Farzaneh P, Mahdavi N, Vakhshiteh F, Karimi A, Gohari NS, Kamali F, Kharazifard MJ, et al: Interleukin- 6 secreted by oral cancer-associated fibroblast accelerated VEGF expression in tumor and stroma cells. Cell Mol Biol (Noisy-le-grand) 63: 131-136, 2017.

14. Weidner N, Semple JP, Welch WR and Folkman J: Tumor angiogenesis and metastasis-correlation in invasive breast carcinoma. N Engl J Med 324: 1-8, 1991.

15. Livak KJ and Schmittgen TD: Analysis of relative gene expression data using real-time quantitative PCR and the 2(-Delta Delta C(T)) method. Methods 25: 402-408, 2001.

16. Tabebordbar M, Zhu K, Cheng JKW, Chew WL, Widrick JJ, Yan WX, Maesner C, Wu EY, Xiao R, Ran FA, et al: In vivo gene editing in dystrophic mouse muscle and muscle stem cells. Science 351: 407-411, 2016.
17. Schiattarella GG, Altamirano F, Tong D, French KM, Villalobos E, Kim SY, Luo X, Jiang N, May HI, Wang ZV, et al: Nitrosative stress drives heart failure with preserved ejection fraction. Nature 568: 351-356, 2019.

18. Holm Nielsen S, Willumsen N, Leeming DJ, Daniels SJ, Brix S, Karsdal MA, Genovese F and Nielsen MJ: Serological assessment of activated fibroblasts by alpha-smooth muscle actin $(\alpha$-SMA): A noninvasive biomarker of activated fibroblasts in lung disorders. Transl Oncol 12: 368-374, 2019.

19. Casparis S, Borm JM, Tektas S, Kamarachev J, Locher MC, Damerau G, Grätz KW and Stadlinger B: Oral lichen planus (OLP), oral lichenoid lesions (OLL), oral dysplasia, and oral cancer: Retrospective analysis of clinicopathological data from 2002-2011. Oral Maxillofac Surg 19: 149-156, 2015.

20. Varricchi G, Granata F, Loffredo S, Genovese A and Marone G: Angiogenesis and lymphangiogenesis in inflammatory skin disorders. J Am Acad Dermatol 73: 144-153, 2015.

21. Balogh E, Biniecka M, Fearon U, Veale DJ and Szekanecz Z: Angiogenesis in inflammatory arthritis. Isr Med Assoc J 5: 345-352, 2019.

22. Shu DY and Lovicu FJ: Myofibroblast transdifferentiation: The dark force in ocular wound healing and fibrosis. Prog Retin Eye Res 60: 44-50, 2017.

23. Villalobos E, Criollo A, Schiattarella GG, Altamirano F, French KM, May HI, Jiang N, Nguyen NUN, Romero D, Roa JC, et al: Fibroblast primary cilia are required for cardiac fibrosis. Circulation 139: 2342-2357, 2019.

24. Kordbacheh F, Bhatia N and Farah CS: Patterns of differentially expressed genes in oral mucosal lesions visualised under autofluorescence (VELscope $\left({ }^{\mathrm{TM}}\right)$ ). Oral Dis 22: 285-296, 2016.

25. Scardina GA, Ruggieri A, Messina P and Maresi E: Angiogenesis of oral lichen planus: A possible pathogenetic mechanism. Med Oral Patol Oral Cir Bucal 14: e558-e562, 2009.

26. Mittal N, Shankari GM and Palaskar S: Role of angiogenesis in the pathogenesis of oral lichen planus. J Oral Maxillofac Pathol 16: 45-48, 2012.

27. Seyedmajidi M, Shafaee S, Bijani A and Bagheri S: VCAM1 and ICAM1 expression in oral lichen planus. Int J Mol Cell Med 2: 34-40, 2013.

28. Mardani M, Ghabanchi J, Fattahi MJ and Tadbir AA: Serum level of vascular endothelial growth factor in patients with different clinical subtypes of oral lichen planus. Iran J Med Sci 37: 233-237, 2012.

29. Scardina GA, Ruggieri A, Maresi E and Messina P: Angiogenesis in oral lichen planus: An in vivo and immunohistological evaluation. Arch Immunol Ther Exp (Warsz) 59: 457-462, 2011.

30. Hazzaa HH, El-Wakeel NM, Attia EA and Abo Hager EA: ALK1 expression in oral lichen planus: A possible relation tomicrovessel density. J Oral Pathol Med 45: 373-380, 2016.

31. Liao YP, Schaue D and McBride WH: Modification of the tumor microenvironment to enhance immunity. Front Biosci 12 : 3576-3600, 2007.

32. Al-Ansari MM and Aboussekhra A: ATR suppresses the pro-tumorigenic functions of breast stromal fibroblasts. Oncotarget 9: 34681-34690, 2018.

33. Hendrayani SF, Al-Harbi B, Al-Ansari MM, Silva G and Aboussekhra A: The inflammatory/cancer-related IL-6/STAT3/NF- $\kappa$ B positive feedback loop includes AUF1 and maintains the active state of breast myofibroblasts. Oncotarget 7: 41974-41985, 2016.

34. Meyer K, Hodwin B, Ramanujam D, Engelhardt S and Sarikas A: Essential role for premature senescence of myofibroblasts in myocardial fibrosis. J Am Coll Cardiol 67: 2018-2028, 2016.

35. Nagasaki T, Hara M, Nakanishi H, Takahashi H, Sato M and Takeyama H: Interleukin- 6 released by colon cancer-associated fibroblasts is critical for tumour angiogenesis: Anti-interleukin-6 receptor antibody suppressed angiogenesis and inhibited tumour-stroma interaction. Br J Cancer 110: 469-478, 2014.

This work is licensed under a Creative Commons Attribution-NonCommercial-NoDerivatives 4.0 International (CC BY-NC-ND 4.0) License. 